\title{
RELEITURA DA CLASSIFICAÇÃO DE KÖPPEN PARA DEMONSTRAR A VARIABILIDADE CLIMÁTICA: PROPOSTA PARA FORMAÇÃO DE PROFESSORES
}

\author{
Köppen classificationretrievaltodemonstrateclimatevariability: a proposal for teacher \\ training
}
Recuperacióndel sistema de Köppen para demostrar lavariabilidad climática: una propuesta para laformación de profesores

\begin{abstract}
Ricardo de Jesus Brandolt*
*Pós-Graduando no Mestrado acadêmico, pertencendo à linha de pesquisa Análise Ambiental do Programa de Pós-Graduação em Geografia, da Universidade Federal de Pelotas

Recebido em 20/10/2019. Aceito para publicação em 20/10/2019.

Versão online publicada em 10/11/2019 (http://seer.ufrgs.br/paraonde)
\end{abstract}

\section{Resumo:}

Neste trabalho se propõe um exercício para o ensino de climatologia no qual se aplica a velha classificação climática de Köppen, porém de uma forma renovada. Ao invés de usarem-se as médias climáticas de 30 anos por estação meteorológica, propõe-se o uso das médias ou totais mensais, ano a ano. Explica-se uma metodologia de aplicação usando planilha eletrônica em EXCEL, contudo, o mesmo processo pode ser realizado de modo analógico, desde que estejam claros os limiares de cada caractere (letra). Também se apresenta dois exemplos: um restrito a duas localidades, mas para um tempo mais longo e outro, aplicado à 16 estações INMET do Rio Grande do Sul, para um período de 11 anos. Este exercício propicia a compreensão do significado dos caracteres da classificação climática ainda majoritariamente utilizada. Além disso, permite constatar que os tipos climáticos definidos a partir de normais climatológicas têm em si uma significativa variabilidade interanual.

Palavras-chave: Tipo Climático. Köppen.Variabilidade Interanual.

\begin{abstract}
:
This paper proposes an exercise for the teaching of climatology in which the old climate classification of Köppen is applied, but in a renewed way. Instead of using 30year climate averages per weather station, it proposes to use the classification to define "Annual Climate Types". An application methodology using EXCEL spreadsheet is explained, however, the same process can be performed analogously as long as the thresholds of each character (letter) are clear. Two examples are also presented: one restricted to two locations, but for a longer time and the other applied to 16 INMET stations in Rio Grande do Sul, for a period of 11 years. This exercise provides an understanding of the meaning of the most widely used climate classification characters. In addition, it can be seen that climate types defined from climatological normals have significant interannual variability.
\end{abstract}

Key-words:Type of Climate, Köppen, Interannual Variability

\section{Resumen:}

Este artículo propone un ejercicio para la enseñanza de climatología en el que se aplica la antigua clasificación climática de Köppen, pero de manera renovada. En 
lugar de utilizar promedios climáticos de 30 años por estación meteorológica, propone utilizar la clasificación para definir "Tipos de clima anuales". Se explica una metodología de clasificación que utiliza la hoja de cálculo EXCEL, sin embargo, el mismo proceso se puede realizar de manera análogica siempre que los umbrales de cada carácter (letra) estén claros. También se presentan dos ejemplos: uno restringido a dos ubicaciones, pero por más tiempo y el otro aplicado a 16 estaciones INMET en Rio Grande do Sul, por un período de 11 años. Este ejercicio proporciona una comprensión del significado de los caracteres de clasificación climática más utilizados. Además, se puede ver que los tipos de clima definidos a partir de las normales climatológicas tienen una variabilidad interanual significativa.

Palabras-clave:Tipo climático, Köppen, Variabilidad interanual.

\section{INTRODUÇÃO}

Wladimir Köppen (1918) concebeu sua classificação climática a partir da concepção de clima como "o conjunto de fenômenos meteorológicos que caracterizam o estado médio da atmosfera e que influenciam de forma direta e indiretamente a vida animal e vegetal sobre um determinado lugar". Nesta definição, é ressaltado o fato de o clima representar o que é esperado, baseado em valores médios dos estados da atmosfera para longo período de tempo.

Nas aulas de climatologia nos cursos de formação de professores em geografia a classificação de Köppen é, normalmente, renegada por seu caráter estanque e por ser considerada uma abstração desconectada da realidade. Como observou Dubreuil et al (2017), o caráter estático e estanque da classificação climática de Köppen no Brasil tem sido criticada por diversos autores (Monteiro, 1971; Sant'anna Neto, 2013; Mendonça e Danni-Oliveira, 2007), de maneira que, atualmente, a climatologia trabalhada por geógrafos prefere a abordagem rítmica da gênese e sucessão de tipos de tempo propostos por Monteiro $(1968,1971)$ ou sinóptico (Nimer, 1989) ou abordagens próximas ao que foi proposto por Strahler (1989).

De fato, a base em dados médios de 30 anos de observação dá a esta classificação um caráter que mascara a variabilidade climática anual relacionada às teleconexões e, ainda possíveis tendências do clima relacionadas à mudanças climáticas. Por isso é necessário partir para análises de tempo mais curto. Neste trabalho, propomos a realização de um exercício relativamente simples com estudantes de geografia, que propicie o entendimento da variabilidade climática, sem a necessidade de recorrer a métodos estatísticos complexos ou meses de análise de cartas sinóticas. A proposta é continuar usando os limiares propostospor Köppen, porém não aplicados às médias calculadas durante um longo período (30 anos), e sim para cada ano considerado de forma independente, definindo assim um "Tipo Climático Anual" (TCA) para cada ano considerado, como proposto por DUBREUIL et al. (2017).

A Organização Meteorológica Mundial (OMM) define Normais Climatológicas (NC) como "valores médios calculados para um período relativamente longo e uniforme, compreendendo no mínimo três décadas consecutivas" e padrões climatológicos normais como "médias de dados climatológicos calculadas para períodos consecutivos de 30 anos" (INMET, 2017). Assim, como acontece em análises geoeconômicas, em que a renda per capita não mostra a real desigualdade

ParaOnde!?, Porto Alegre, v.12 n.2, p.252-261, 2019.http://seer.ufrgs.br/paraonde Edição Especial - III Colóquio de Pesquisadores em Geografia Física Ensino de Geografia 
de renda que existe num país, ou região, o mesmo se pode dizer sobre o clima médio, que pode se compor por uma variabilidade muito grande de um ano para o outro. Um pouco desta variabilidade é que o TCA vai mostrar.

$\mathrm{Na}$ sequência, explica-se a metodologia de aplicação da classificação com base na NC-1981-2010 e com base no dado anual para duas estações meteorológicas no estado do Rio Grande do Sul. Posteriormente apresentam-se os resultados deste exemplo e também o resultado dos TCA para 16 estações meteorológicas neste estado no período 2007 a 2017.

Esta prática de ensino tem como objetivo demonstrar a variabilidade climática anual não com base nos métodos estatísticos de variabilidade, mas sim com base nos parâmetros empíricos propostos por Koppen, aplicados aos dados mensais de temperatura média e precipitação de cada ano.

\section{METODOLOGIA}

A classificação climática de Köppen distingue os climas em função dos seus regimes térmicos ( $A, C, D, E$ e subtipos $a, b, c, d, h$ e i) e pluviométricos (BW, BS e subtipos, m, s e w). Como o Brasil tem 93\% do território no Hemisfério Sul, para a maioria das estações meteorológicas, consideram-se meses de verão - dezembro, janeiro, fevereiro (DJF) - e meses de inverno - junho, julho, agosto (JJA).

A primeira letra do tipo climático do Rio Grande do Sul, por exemplo, é C que significa um Clima mesotérmico, com temperatura média do ar dos 3 meses mais frios compreendidas entre $-3^{\circ} \mathrm{C}$ e $18^{\circ} \mathrm{C}$ e temperatura média do mês mais quente superior a $10^{\circ} \mathrm{C}$ e estações de verão e inverno bem definidas.

Para os climas $\mathrm{C}$, o regime pluviométrico identifica a segunda letra, com os subtipos: w (inverno seco) - que ocorre nos anos em que o mês menos chuvoso do inverno recebe menos de $1 / 10$ das precipitações do mês mais chuvoso do verão e a precipitação mínima do inverno é menor que a precipitação mínima do verão; s (verão seco) - está relacionado aos anos em que o mês menos chuvoso do verão recebe menos de $1 / 3$ da precipitação do mês mais chuvoso de inverno, a precipitação mínima do verão é menor $40 \mathrm{~mm}$ e também menor que a mínima do inverno; $f$ - atribuído aos anos que não se classificam nem e s nem em w (KOTTEK et al., 2006; DUBREUIL et al., 2017), porém úmido, não sendo passível de encaixe nos climas do grande tipo $B$.

A terceira letra dos grupos climáticos " $C$ " e "D" refere-se às condições térmicas do verão que, na classificação de Köppen. Portanto, no grupo "C", os subtipos "a" e "b" se aplicam igualmente aos tipos "Cs", "Cw" ou "Cf". Köppen (1918) propôs diferenciar os de verões quentes (temperatura média do mês mais quente superior a $22^{\circ} \mathrm{C}$ para o tipo a) daqueles com verões frescos (temperatura média do mês mais quente abaixo de $22^{\circ} \mathrm{C}$ para o tipo b).

Antes da classificação foi realizado o ordenamento dos dados tanto da NC1981-2010 como para os anos em separado, conforme metodologia proposta por DUBREUIL et al. (2017). Nesta proposta didática, como exemplo, a metodologia de classificação foi aplicada aos dados de duas localidades que dispõe de estação do

ParaOnde!?, Porto Alegre, v.12 n.2, p.252-261, 2019.http://seer.ufrgs.br/paraonde Edição Especial - III Colóquio de Pesquisadores em Geografia Física Ensino de Geografia 
Instituto Nacional de Meteorologia (INMET) por longa data: Santa Vitória (OMM83997) do Palmar e TorresOMM- 83948). Os dados obtidos no Banco de dados para Ensino e Pesquisa (BDMEP) do INMET. Na fase da análise e tratamento dos dados no ambiente do programa Excel, foram constatadas falhas temporais em alguns meses. Nos anos 1980 e 1990 há muitas falhas na base dos dados das estações do INMET, o que exige ainda um trabalho de preenchimento destas falhas. Das 360 medições mensais base que se parte a análise térmica e pluviométrica sobre a Normal Climatológica e resultando no TCA, na estação de Santa Vitória do Palmar houveram 72 falhas no registro dos dados mensais, $20 \%$ em relação ao número total de medições.

Os dados foram organizados em planilhas, definindo-se condicionantes conforme os limiares das chaves de classificação estabelecidas. Em cada coluna foi utilizada uma fórmula específica que calcula os limites definidos pela metodologia, buscando valores em posições específicas da série histórica.

Ressalta-se que a análise proposta recai sobre o Tipo e Subtipo climáticos, permanecendo os dois municípios no mesmo grande Grupo climático "C". Neste caso, os limites estatísticos definidos por Koppen (1918) para a segunda e terceira letrada classificação foram aplicados em fórmulas no Excel, localizando e retornando os valores referentes aos diferentes tipos climáticos: para o tipo $C w$ foi necessário encontrar o valor do mês menos chuvoso do inverno para que fosse comparado com o mês mais chuvoso do verão; da mesma forma que para o tipo Cs foi preciso encontrar o valor do mês menos chuvoso do verão para ser relacionado com o mês mais chuvoso do inverno. Por fim, para o tipo $C w$, o ano precisa apresentar o mês menos chuvoso do inverno com precipitação menor ou igual à 1/10 da precipitação do mês mais chuvoso do verão. Para isto foram aplicadas as seguintes fórmulas (Quadro1):

\section{Quadro 1- Fórmulas para identificar se há TCA de tipo "Cw".}

Fórmula1 "=MENOR(SantaVitoria!\$D\$8:\$D10;1)" Fórmula3 "=Fórmula2/10"

Fórmula2 "=MAIOR(SantaVitoria!\$D\$2:\$D\$4;)" Fórmula4 "=SE(Fórmula1<=Fórmula3;"w";"NÃO")"

Fonte: Koppen (1918). Organizado pelos autores.

Já para que o tipo seja $C s$, o ano precisa apresentar a precipitação do mês menos chuvoso do verão menor ou igual à $1 / 3$ da precipitação do mês mais chuvoso do inverno, e para que o software pudesse retornar esses valores foram utilizadas as fórmulas do quadro 2:

\section{Quadro 2- Fórmulas para identificar se há TCA de tipo "Cs".}

\begin{tabular}{|l|l|l|l|}
\hline Fórmula1 "=MENOR(SantaVitoria!\$D\$2:\$D\$4;1)" & Fórmula3 "=Fórmula2/3" \\
\hline Fórmula2 "=MAIOR(SantaVitoria!\$D\$8:\$D\$10;1)" & Fórmula4 "=SE(Fórmula1<=Fórmula3;"s";"NÃO")"
\end{tabular}

Fonte: Koppen (1918). Organizado pelos autores.

A definição do Tipo $f$ deve-se à não correspondência dos tipos w e $s$ (Quadro 3 ), onde a fórmula precisou filtrar as classificações dos referidos tipos de clima para

ParaOnde!?, Porto Alegre, v.12 n.2, p.252-261, 2019.http://seer.ufrgs.br/paraonde Edição Especial - III Colóquio de Pesquisadores em Geografia Física Ensino de Geografia 
que, havendo a negação de ambos, a instrução retornasse o tipo $f$.

Quadro 3- Fórmula para identificar se há TCA de tipo "Cf”.

Fórmula1 "=SE(E44="w";"Não";SE(I44="s";"Não";"f"))"

Fonte: Koppen (1918). Organizado pelos autores.

OsSubtipos ,segundoKöppen, considerando as variações sazonais de temperatura, se definem conforme os seguintes parâmetros: subtipo amédia do mês mais quente é superior a $22^{\circ} \mathrm{C}$; para o subtipo $b$, a média do mês mais quente é inferior à $22^{\circ} \mathrm{C}$, como mostra o quadro 4.

Quadro 4 - Fórmulas para identificar o subtipo climático.

Fórmula1 "=SE(E44="w";"w";SE(I44="s";"s";"f"))"

Fórmula2 "=SE(K44>22;"a";"b")"

Fonte: Koppen (1918). Organizado pelos autores.

A disposição dos dados e fórmulas para o cálculo do TCA ficou configurada de acordo com o quadro 5.

Quadro 5- Disposição dos dados por ano e estação no cálculo do TCA.

\begin{tabular}{|c|c|c|c|c|c|c|c|c|c|c|c|}
\hline \multicolumn{10}{|c|}{ TIPO } & \multicolumn{2}{|c|}{ SUBTIPO } \\
\hline \multicolumn{4}{|c|}{ INVERNO-chuvoERAO+chuvosmm + chuva I } & $w$ & \multicolumn{3}{|c|}{ ERAO-chuvos/ERNO+chuve + chuva inve } & $\mathrm{s}$ & $f$ & mês+quente & $a / b$ \\
\hline 1981 & 25,5 & 44 & 4,4 & NÃO & 38,5 & 166,3 & 55,4 & $\mathrm{~s}$ & NÃO & 22,7 & $a$ \\
\hline 1982 & 76,1 & 281,3 & 28,13 & NÃO & 29,3 & 166,2 & 55,4 & s & NÃO & 21,5 & $b$ \\
\hline 1983 & 116,1 & 105,6 & 10,56 & NÃO & 26,4 & 158,3 & 52,8 & $\mathrm{~s}$ & NÃO & 23,2 & a \\
\hline 1984 & 80,1 & 296,4 & 29,64 & NÃO & 51,3 & 249,3 & 83,1 & $\mathrm{~s}$ & NÃO & 23,6 & a \\
\hline
\end{tabular}

Fonte: Koppen (1918). Organizado pelos autores.

Duas colunas foram criadas para retornar automaticamente, segundo a instrução dada, os tipos e subtipos identificados, realizando a filtragem de caráter eliminatório entre a presença ou não dos tipos $w, s$ ou $f$ e dos subtipos $a$ e $b$, respectivamente (Quadro 6).

Quadro 6 - Exemplo da construção tabelada dos TCA de Santa Vitória do Palmar.

\begin{tabular}{|c|c|c|c|c|}
\hline \multicolumn{5}{|c|}{ Santa Vitória do Palmar } \\
\hline Ano & Grupo & Tipo & Subtipo & \\
\hline 1981 & C & s & a & Csa \\
\hline 1982 & C & s & b & Csb \\
\hline 1983 & C & s & a & Csa \\
\hline
\end{tabular}

Fonte: INMET (2018). Organizado pelos autores. 
Após a classificação dos TCA foram elaborados gráficos de distribuição de frequência destes tipos no local da estação meteorológica para o período proposto.

Para a realização de um exercício em sala de aula, não há necessidade de fazer uso da planilha Excel. $O$ trabalho também pode ser realizado com as planilhas impressas, simplesmente analisando os dados mensais de cada ano. É uma forma de o estudante se impregnar do significado de uma classificação climática.

\section{RESULTADOS E DISCUSSÕES}

Segundo os dados da NC-1981-2010, tanto Torres como Santa Vitória do Palmar enquadram-se no Tipo Climático "Cfa". Assim, no longo prazo, estas duas localidades apresentam clima temperado sem estação seca e verão quente.

Já quando analisados os anos em separado, as localidades apresentam comportamento diferenciado (Figura 1). Assim, em Santa Vitória do Palmar $52 \%$ dos anos analisados foram classificados como tipo climático Csa, ou seja, clima mediterrânico com verão quente e seco e, somente, em 35\% dos anos foi constatado o tipo climático Cfa detectado na análise com base na da NC. Torres continuou apresentando predominância do tipo climático definido através da NC, Cfa, em $58 \%$ dos anos analisados; enquanto o tipo Csa ocorreu somente em $34 \%$ dos anos analisados.

Figura 1 - Participação dos TCA para os anos válidos entre 1981 e 2010.

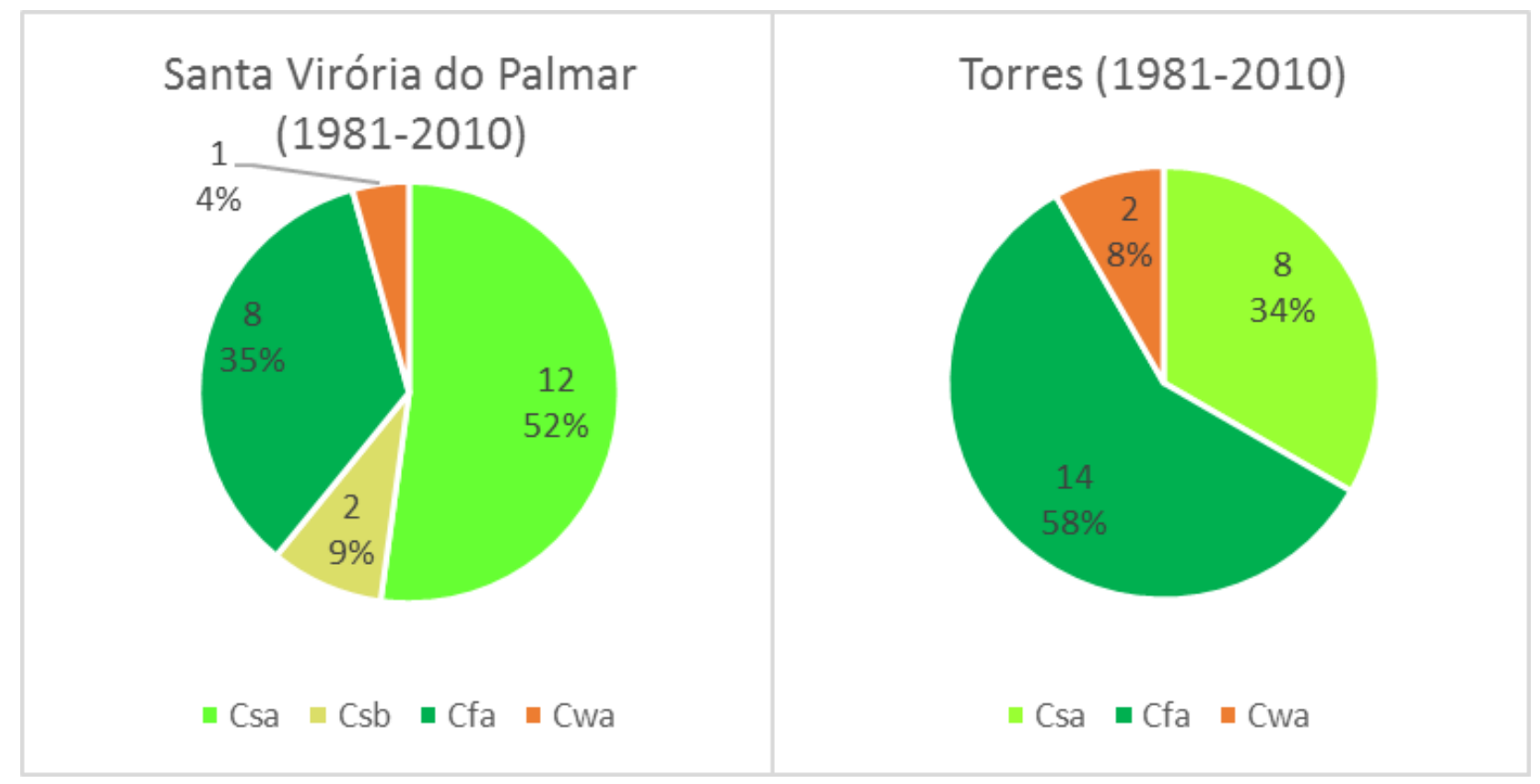

Fonte: INMET (2018). Organizado pelos autores.

Em outro exemplo, foram identificados o TCA para 16 estações meteorológicas do INMET no Rio Grande do Sul, desde o ano 2007 até o 2017.

Segundo Matzenauer, Radin e Almeida (2011), que interpolaram os dados da NC-1061-1990 para as estações meteorológicas do Rio Grande do Sul e aplicaram a

ParaOnde!?, Porto Alegre, v.12 n.2, p.252-261, 2019.http://seer.ufrgs.br/paraonde Edição Especial - III Colóquio de Pesquisadores em Geografia Física Ensino de Geografia 
classificação de Köppen, o conjunto do estado corresponde a zona temperada tipo "C" e ao domínio "Cf" ou temperado úmido, com precipitação bem distribuída ao longo do ano. No estado, de acordo com as normais climatológicas, o "Cf", (Moreno, 1961; Matzenauer, Radin, e Almeida, 2011) ocorre em duas variedades específicas "Cfa" et "Cfb". O tipo "b" se limitam aos topos dos Planaltos Arenito Basáltico, a norte, e Sulriograndense, a sul, enquanto que a maior parte do território se enquadra no tipo "a".

O mapa da figura 2 representa, para cada uma das dezesseis estações meteorológicas, a freqüência de cada TCA durante o período 2007-2017. 2017.

Figura 2 -Frequência dos TCA no Rio Grande do Sul para o período 2007-

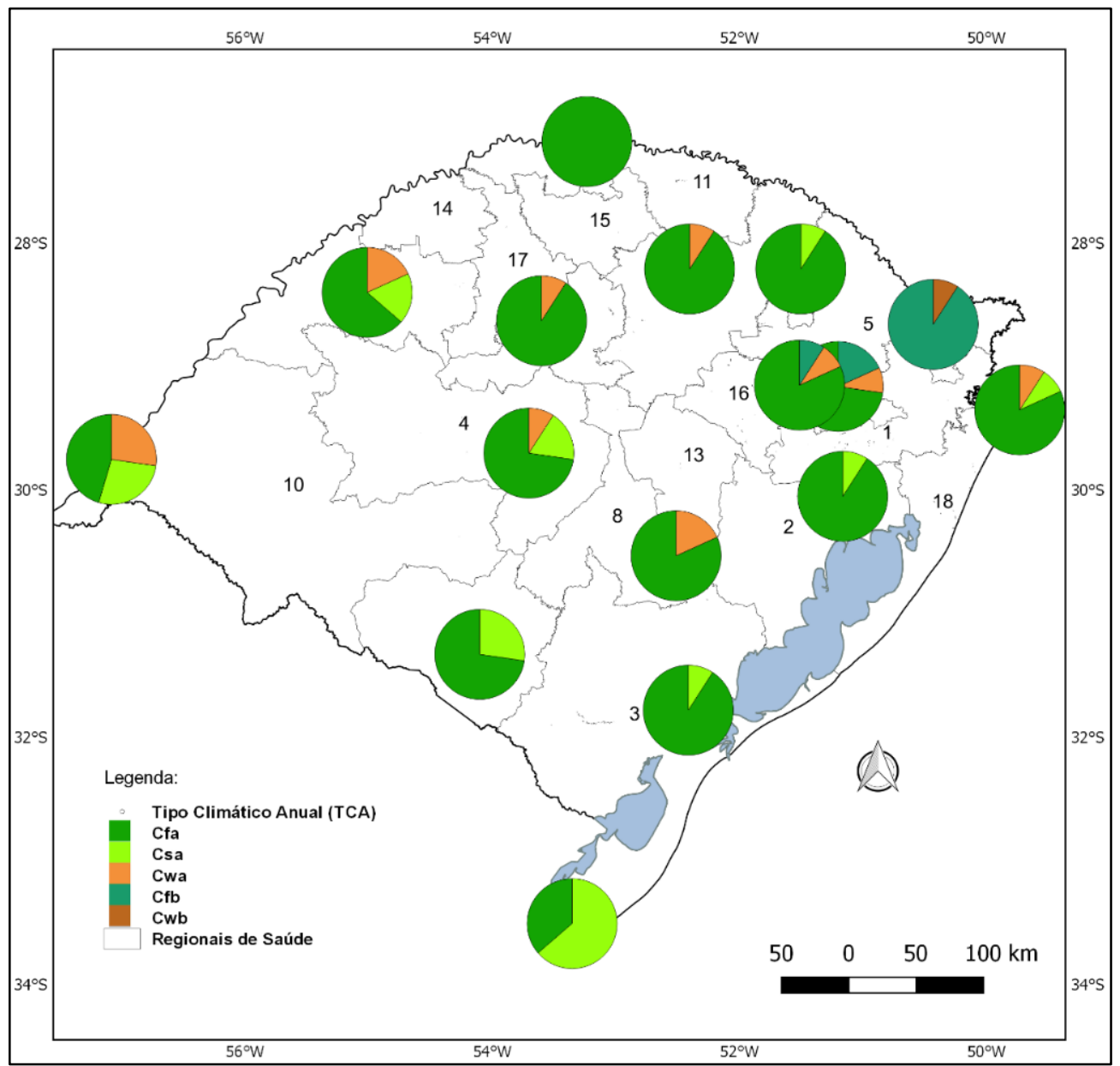

Fonte: COLLISCHONN, DUBREUIL e MENDONÇA, 2017.

Como mostra a figura o TCA "Cfa" é o que predomina no Rio Grande do Sul: na estação Iraí ocorreu todos os anos e, em outras cinco, este tipo climático ocorreu em 10 dos 11 anos, em três estações ocorreu em 9 anos e, em três, em 8 dos 11 anos analisados. Porém, para algumas estações meteorológicas, principalmente as do sul e oeste do estado, apareceu com frequência o tipo Csa, com seca no verão. O tipo $\mathrm{Cfb}$ que, no mapa da figura 2, abrange uma área mais extensa, predominou em termos de tipo climático anual, somente na estação de Bom Jesus, ocorrendo em menor frequência nas estações meteorológicas de Bento Gonçalves e Caxias do

ParaOnde!?, Porto Alegre, v.12 n.2, p.252-261, 2019.http://seer.ufrgs.br/paraonde Edição Especial - III Colóquio de Pesquisadores em Geografia Física Ensino de Geografia 
Sul. Este tipo não foi registrado em Lagoa Vermelha e Encruzilhada do Sul, estações às quais o $\mathrm{Cfb}$ é atribuído como Tipo Climático médio. Ainda ocorreram, com alguma frequência no centro e norte do estado, as variantes Cwa e Cwb, com um regime de chuvas marcado pela tropicalidade (com período seco no inverno e verão muito chuvoso).

Esta abordagem de frequência permite uma nova representação cartográfica de climas, distinguindo núcleos fortes e zonas de transição. Os primeiros designam as regiões onde se destaca predominantemente o TCA, como a vasta extensão do tipo "Cfa" no estado. As áreas de transição, por outro lado, experimentam uma variedade de influências climáticas e aí aparecem TCA diferenciados.

\section{CONSIDERAÇÕES FINAIS}

Através deste exemplo, pode-se mostrar que mais de um século após a sua concepção, o método de classificação climática de Köppen ainda permite que diferenciações climáticas regionais sejam evidenciadas, desde que subverta a versão inicial estabelecida em valores médios de muitos anos. A abordagem do tipo climático anual (TCA) renova o método, levando em consideração, explicitamente, a variabilidade interanual do clima: mostra que o tipo médio de clima de Köppen nem sempre é aquele observado em todos os anos numa determinada estação. $\mathrm{Na}$ análise detalhada mostrada para as duas estações do litoral, Santa Vitória do Palmar e Torres, constatou-se que o tipo climático predominante não necessariamente não corresponde à classificação de Koppen pela NC-1981-2010. Já na análise para o Rio Grande do Sul no período 2007-2017, o tipo "Cfa" só não foi o tipo mais frequente nas estações Santa Vitória do Palmar, onde o "Csa" foi mais frequente e em Bom Jesus, onde predominou o "Cfb"; contudo, percebe-se uma variabilidade regional quanto a frequência das tipologias.

Por ser um método de classificação climática simples, que pode ser aplicado mesmo sem o uso de planilhas eletrônicas, a realização de um exercício de classificação climática usando o método do TCA pode ser aplicado em curso de formação de professores de Geografia.

\section{REFERÊNCIAS}

COLLISCHONN E., DUBREUIL V., MENDONÇA F. A. Variabilitéduclimat et de la dengue dansl'Etatdu Rio Grande do Sul (Brésil) pourlapériode 2007 à 2017. XXXIeColloqueAnnuel de l'AssociationInternationale de Climatologie (AIC 2018), NICE (FRANCE) de 4 a 7 de julho 2018.

DUBREUIL, V.; FANTE, K. P.I; PLANCHON, O.; SANT'ANNA NETO, J. L. Lestypes de climatsannuelsauBrésil : une application de laclassification de Köppen de 1961 à 2015. EchoGéo, n.41, juillet/septembre, p. 1-27, 2017.

INSTITUTO NACIONAL DE METEOROLOGIA (INMET). Banco de Dados Meteorológicos para Ensino e Pesquisa. « Dados da Rede do INMET» 2017. Disponível em: http://www.inmet.gov.br/projetos/rede/pesquisa/inicio.php.

ParaOnde!?, Porto Alegre, v.12 n.2, p.252-261, 2019.http://seer.ufrgs.br/paraonde Edição Especial - III Colóquio de Pesquisadores em Geografia Física Ensino de Geografia 
Acesso em mio 2018.

INSTITUTO NACIONAL DE METEOROLOGIA (INMET). Normais Climatológicas do Brasil 1981-2010, 2017, Brasília, DF. Disponível em: http://www.inmet.gov.br/portal/index.php?r=clima/normaisclimatologicas.

Acessoem 10 ago de 2018.

KÖPPEN, W. Klassifikation der Klimate, nachTemperatur, Niederschlag und Jahreslauf. PettermannsGeographischeMitteilung, 64, p. 193-203 e p.243248 , 1918. Disponívelem koeppen-geiger.vu-wien.ac.at/pdf/Koppen_1918.pdf

KOTTEK, M.; GRIESER, J.; BECK, C.; RUDOLF, B. ; RUBEL, F. World Map of the Köppen-Geiger climate classification updated. MeteorologischeZeitschrift, Vol. 15, No. 3, jun 2006. p. 259-263

MATZENAUER, Ronaldo; RADIN, Bernadete; ALMEIDA, Ivan Rodrigues de. (Ed.). Atlas Climático: Rio Grande do Sul. Porto Alegre: Secretaria da. Agricultura Pecuária e Agronegócio; Fundação Estadual de Pesquisa. Agropecuária (FEPAGRO), 2011.

MENDONÇA F., Danni-Oliveira I. M., 2007. Clima: Noções básicas e climas do Brasil. São Paulo, Oficina de Textos.

MONTEIRO, C.A.F., 1968. Clima. In: Geografia do Brasil: A grande região Sul. IBGE, p. 4

MONTEIRO, C.A.F., 1971. Analise rítmica em climatologia. Climatologia 1, USP/IG, São Paulo, p. 1-21.

NIMER E., 1989. Climatologia do Brasil. IBGE, Rio de Janeiro, 421 p.

ORGANIZAÇÃO METEOROLÓGICA MUNDIAL . Calculation of monthly and annual 30-year standard normals .Geneva, 1989. (WMO .Technicaldocument, n . 341; WCDP, n .10) .

SANT'ANNA Neto J.L., 2013. A climatologia geográfica no Brasil: origem e contexto histórico. In AMORIM, M. C. T.; SANT'ANNA NETO, J. L.; MONTEIRO, A. (Org.), Climatologia Urbana e Regional: questões teóricas e estudos de caso. 1ed.São Paulo, Outras Expressões, vol. 1, p. 11-73.

STRAHLER, A. N., 1989. Geografía Física. Omega,Barcelona.

ZAVATINI J.A., 1990. A dinâmica atmoférica e a distribuição das chuvas no Mato Grosso do Sul. Tese de doutorado, Universidade de São Paulo. 